\title{
Results of delayed follow-up imaging in traumatic brain injury
}

\author{
Adam Ross Befeler, MD, MS, ${ }^{1}$ William Gordon, MD, ${ }^{1}$ Nickalus Khan, MD, ${ }^{1}$ Julius Fernandez, MD, ${ }^{1,2}$ \\ Michael Scott Muhlbauer, MD, ${ }^{1,2}$ and Jeffrey Marius Sorenson, MD ${ }^{1,2}$ \\ 'Department of Neurosurgery, University of Tennessee Health Science Center; and ${ }^{2}$ Semmes-Murphey Neurological and Spine \\ Institute, Memphis, Tennessee
}

\begin{abstract}
OBJECTIVE There is a paucity of scientific evidence available about the benefits of outpatient follow-up imaging for traumatic brain injury patients. In this study, 1 year of consecutive patients at a Level 1 trauma center were analyzed to determine if there is any benefit to routinely obtaining CT of the head at the outpatient follow-up visit.
\end{abstract}

METHODS This single-institution retrospective review was performed on all patients with a traumatic brain injury seen at a Level 1 trauma center in 2013. Demographic data, types of injuries, surgical interventions, radiographic imaging in inpatient and outpatient settings, and outcomes were assessed through a review of the institution's trauma registry, patient charts, and imaging.

RESULTS Five hundred twenty-five patients were seen for traumatic brain injury in 2013 at Regional One Health in Memphis, Tennessee. One hundred eighty-five patients (35\%) presented for outpatient follow-up, all with CT scans of the head. Seven of these patients (4\%) showed worsening of their intracranial injuries on outpatient imaging studies; however, surgical intervention was recommended for only 3 of these patients (2\%). All patients requiring an intervention had neurological deterioration prior to their follow-up appointment.

CONCLUSIONS These experiences suggest that outpatient follow-up imaging for traumatic brain injury should be done selectively, as it was not helpful for patients who did not exhibit worsening of neurological signs or symptoms. Furthermore, routine outpatient imaging results in unnecessary resource utilization and radiation exposure.

http://thejns.org/doi/abs/10.3171/2015.4.JNS141257

KEY WORDS traumatic brain injury; outpatient imaging; head injury; delayed imaging; trauma

$\mathrm{T}$ RAUMATIC brain injury (TBI) is the leading cause of death and disability in children and adults between the ages of 1 and 44 years..$^{10}$ Approximately 52,000 deaths result each year because of TBI, and approximately 5.3 million Americans currently live with disabilities resulting from TBI. ${ }^{10}$ Several studies have examined the utility of routine early inpatient follow-up imaging in patients with TBI. ${ }^{2,4-6,13}$ However, the evidence guiding the outpatient follow-up imaging of these patients is lacking. Furthermore, as radiographic imaging studies continue to grow in use, patients are exposed to more radiation from health care..$^{14}$ In our trauma practice, we have routinely obtained CT scans of the head for TBI patients at the time of their 30-day follow-up visit. Over time, however, most of our physicians have developed the opinion that these scans are rarely helpful. Therefore, the goal of our study was to assess the impact of outpatient follow-up CT scans on the care of TBI patients.

\section{Methods}

This single-institution retrospective chart review was performed at Regional One Health ( $\mathrm{ROH})$ in Memphis, Tennessee-the only American College of Surgeons Level 1 trauma center serving a 150-mile radius that includes western Tennessee, as well as parts of Arkansas, Mississippi, Kentucky, and Missouri.

The study criteria included patients 15 years of age or older who suffered either blunt or penetrating TBI between January 1, 2013, and December 31, 2013. These patients 
were retrospectively identified using the $\mathrm{ROH}$ trauma registry. Only patients with a trauma-related abnormality of the brain on CT imaging were included. Institutional review board approval was obtained from both the University of Tennessee and $\mathrm{ROH}$ prior to initiating the study.

Patient charts were reviewed, including all emergency department physician and nursing notes, history and physical examinations, consultations, progress notes, radiology imaging and reports, operative and procedural notes, and follow-up office records from the neurosurgical outpatient offices. Demographic data for each patient were collected, including age, sex, race, insurance source, medical history, prior neurological disorders, history of smoking, history of substance abuse, history of anticoagulation or antiplatelet agent use, date of injury, mechanism of injury, Glasgow Coma Scale (GCS) score on arrival, intubation during hospitalization or prior to hospitalization, type of intracranial injury identified via imaging modalities, skull fractures, severity of injuries, additional major injuries, neurosurgical interventions including bedside procedures and/ or operative procedures, length of hospitalization, number of repeat inpatient CT scans of the head, outpatient imaging, outpatient neurological examination, and outcomes including any interventions performed. Additionally, the cost of repeat imaging studies at our center was analyzed via standardized charge analysis. All statistics were calculated using SPSS version 21 (IBM) and R (http://www.Rproject.org). The mean \pm standard deviation is presented for all values.

\section{Results \\ Demographics}

During 2013, 525 patients were treated for TBI at ROH. Among these 525 patients, 103 patients (20\%) died during their hospitalization. From the remaining 422 patients, 185 patients (44\%) presented for follow-up at either the $\mathrm{ROH}$ neurotrauma clinic or the Semmes-Murphey Neurological Institute; the remaining patients were lost to follow-up and were therefore excluded from the study. All patients returning for a clinic visit underwent repeat CT imaging of the brain. The mean age of the population studied was $43 \pm 19$ years with a range between 15 and 87 years. There were 117 (63\%) males and 68 (37\%) females. Comorbidities included coronary artery disease, congestive heart failure, hypertension, diabetes mellitus, prior cerebral vascular accidents, seizure disorders, prior neurological injury, and dementia. Antiplatelet or anticoagulation medications were used by 21 (11\%) patients prior to injury. The length of stay ranged between 1 and 106 days in the acute care hospital, with an average length of stay of $15 \pm$ 17.5 days. See Table 1 for additional demographic data.

\section{Head Injuries}

The patients with TBI included in this study had blunt trauma in 172 cases (93\%), which most commonly involved a motor vehicle collision or penetrating trauma in 13 cases (17\%), which were all gunshot wounds. GCS score upon arrival ranged from 3 to 15 with a mean of $12 \pm 3$. Head injuries were severe (GCS Score 3-8) in $33(18 \%)$ patients, moderate (GCS Score 9-12) in 33 (18\%) patients, and
TABLE 1. Demographics of the study patient population

\begin{tabular}{|c|c|}
\hline Patient Demographics & No. of Patients (\%) \\
\hline \multicolumn{2}{|l|}{ Sex } \\
\hline Male & $117(63)$ \\
\hline Female & $68(37)$ \\
\hline \multicolumn{2}{|l|}{ Race } \\
\hline Caucasian & $111(60)$ \\
\hline African American & $67(36)$ \\
\hline Other & $7(4)$ \\
\hline \multicolumn{2}{|l|}{ Mechanism } \\
\hline Blunt & $172(93)$ \\
\hline Penetrating & $13(7)$ \\
\hline \multicolumn{2}{|l|}{ GCS score at arrival } \\
\hline $3-8$ & $33(18)$ \\
\hline $9-12$ & $33(18)$ \\
\hline $13-15$ & $119(64)$ \\
\hline Mean & 12 \\
\hline \multicolumn{2}{|l|}{ Intracranial injury } \\
\hline Traumatic SAH & $109(59)$ \\
\hline $\mathrm{aSDH}$ & $76(41)$ \\
\hline $\mathrm{cSDH}$ & $2(1)$ \\
\hline IPH & $91(49)$ \\
\hline IVH & $17(9)$ \\
\hline PCP & $25(14)$ \\
\hline Skull Fx & $74(40)$ \\
\hline Antiplatelet/anticoagulation & $21(11)$ \\
\hline Coumadin & $7(3.8)$ \\
\hline Aspirin, $81 \mathrm{mg}$ & $2(1)$ \\
\hline Aspirin, $325 \mathrm{mg}$ & $2(1)$ \\
\hline Plavix & $2(1)$ \\
\hline Aspirin + Plavix & $3(2)$ \\
\hline Aggrenox & $1(0.5)$ \\
\hline Aspirin + Plavix + Coumadin & $1(0.5)$ \\
\hline Pradaxa + aspirin & $1(0.5)$ \\
\hline Coumadin + aspirin & $1(0.5)$ \\
\hline Effient + aspirin & $1(0.5)$ \\
\hline Neurosurgical intervention & $42(23)$ \\
\hline Craniotomy/craniectomy & $33(18)$ \\
\hline Intraparenchymal monitor & $21(11)$ \\
\hline External ventricular drain & $9(5)$ \\
\hline Ventriculoperitoneal shunt & $1(0.5)$ \\
\hline Lumbar puncture & $1(0.5)$ \\
\hline \multicolumn{2}{|l|}{ Insurance source } \\
\hline Private & $71(38)$ \\
\hline Medicare & $24(13)$ \\
\hline Medicaid & $27(15)$ \\
\hline Uninsured & $56(30)$ \\
\hline Veterans Administration/military & $2(1)$ \\
\hline Workers' compensation & $5(3)$ \\
\hline
\end{tabular}

aSDH = acute subdural hematoma; $\mathrm{CSDH}=$ chronic subdural hematoma; $\mathrm{Fx}$ = fracture; $\mathrm{IPH}=$ intraparenchymal hemorrhage; IVH = intraventricular hemorrhage; $\mathrm{PCP}=$ pneumocephalus; $\mathrm{tSAH}=$ traumatic subarachnoid hemorrhage. 
mild (GCS Score 13-15) in 119 (64\%) patients. The types of intracranial abnormalities seen on initial CT imaging included acute subdural hematoma in $76(41 \%)$ patients, chronic subdural hematoma in $2(1 \%)$ patients, traumatic subarachnoid hemorrhage in 109 (59\%) patients, intraparenchymal hemorrhage in 91 (49\%) patients, intraventricular hemorrhage in $17(9 \%)$ patients, epidural hematoma in $20(11 \%)$ patients, skull fracture in $74(40 \%)$ patients, and pneumocephalus in 25 (14\%) patients.

\section{Inpatient Treatments}

Among the 185 patients who were included in our study, $42(23 \%)$ patients underwent a neurosurgical intervention while in the hospital. This included craniotomy or craniectomy in $33(18 \%)$ patients, placement of an intraparenchymal pressure monitor in $21(11 \%)$ patients, placement of an external ventricular drain in $9(5 \%)$ patients, placement of a ventriculoperitoneal shunt in $1(0.5 \%)$ patient, and lumbar puncture in $1(0.5 \%)$ patient. Additionally, 34 (18\%) patients had significant multiorgan trauma or a surgical emergency involving another organ system.

\section{Inpatient Repeat Imaging}

Of the patients included in our study, inpatient repeat imaging was performed on $184(99.5 \%)$ patients in accordance with our trauma center's TBI protocol, which specifies repeat imaging within 24 hours for patients with acute $\mathrm{CT}$ abnormalities. ${ }^{2} \mathrm{CT}$ findings were noted to be worse in $20(11 \%)$ patients, stable in $140(76 \%)$ patients, better in $12(6 \%)$ patients, and better postoperatively in $12(6 \%)$ patients. One patient $(0.5 \%)$ with minimal traumatic subarachnoid hemorrhage did not undergo inpatient repeat imaging per the protocol, as the attending neurosurgeon judged it to be unnecessary.

\section{Outpatient Repeat Imaging and Examination}

As noted previously, the 185 patients included in this study all underwent repeat imaging as an outpatient before their follow-up office visit, which was typically within 30 days of hospital discharge (mean follow-up of $33 \pm 7$ days). Seven $(4 \%)$ of these patients showed worsening on followup imaging, 3 patients (2\%) had no significant changes, 29 patients $(16 \%)$ had improvement, and 146 patients (79\%) had complete resolution of their intracranial injuries on follow-up imaging studies. Worsening CT findings at the outpatient follow-up included new hydrocephalus, reaccumulation of a chronic subdural hematoma, formation of a subdural hygroma, and formation of chronic subdural hematomas. Among the 7 patients who had worsening on outpatient follow-up imaging, the initial inpatient imaging showed an acute subdural hematoma in $5(71 \%)$ patients, chronic subdural hematoma in $1(14 \%)$ patient, intraparenchymal hemorrhage in $2(29 \%)$ patients, traumatic subarachnoid hemorrhage in $2(29 \%)$ patients, intraventricular hemorrhage in 1 (14\%) patient, and skull fractures in 2 (29\%) patients. See Table 2 for further details. Only 1 patient with worsening outpatient imaging did not have a subdural hematoma on the initial inpatient imaging.

At the time of follow-up, 132 patients (71\%) exhibited clinical improvement, 50 (27\%) patients were stable, and $3(2 \%)$ were clinically worse by history or examination (Tables 2 and 3). All 3 patients who had clinical worsening at follow-up also had worsening of their intracranial findings on outpatient imaging, yet none of them had worsening of their imaging while hospitalized. Among the 3 patients $(2 \%)$ for whom intervention was recommended, none were taking anticoagulation medication before or after the trauma.

\section{Interventions}

Among the 7 patients (4\%) who had radiographic worsening on follow-up imaging, we recommended operative intervention for 3 (2\%) patients. None of these 3 patients had sought medical attention for their worsening symptoms prior to their follow-up appointment.

\section{Case 1}

This 86-year-old man originally presented with a chronic subdural hematoma with a small acute component. He underwent bur hole drainage, but then later returned to the clinic with worsening confusion and reaccumulation of his chronic subdural hematoma. His family elected not to proceed with our recommendation to operate again and instead chose hospice care before his death.

\section{Case 2}

This 23-year-old woman originally presented with a small acute subdural hematoma along the right frontal lobe, a parafalcine acute subdural hematoma, trace intra-

TABLE 2. Outpatient imaging results and interventions stratified by initial CT imaging abnormality

\begin{tabular}{lrrrrrr}
\hline & \multicolumn{5}{c}{ No. of Patients } \\
\cline { 2 - 7 } CT Abnormality & Total & Resolved & Improved & Stable & Worse* & Interventiont \\
\hline aSDH & 76 & $49(64 \%)$ & $18(24 \%)$ & $3(4 \%)$ & $6(8 \%[95 \% \mathrm{Cl} 2.9-17.2 \%])$ & 2 \\
\hline CSDH & 2 & $1(50 \%)$ & $0(0 \%)$ & $0(0 \%)$ & $1(50)$ & 1 \\
\hline IPH & 91 & $68(75 \%)$ & $23(25 \%)$ & $0(0 \%)$ & $0(0 \%[95 \% \mathrm{Cl} \mathrm{0-4 \% ])}$ & 0 \\
\hline IVH & 17 & $16(94 \%)$ & $1(6 \%)$ & $0(0 \%)$ & $0(0 \%[95 \% \mathrm{Cl} 0-21.7 \%])$ & 0 \\
\hline tSAH & 109 & $90(83 \%)$ & $19(17 \%)$ & $0(0 \%)$ & $0(0 \%[95 \% \mathrm{Cl} 0-3.4 \%])$ & 0 \\
\hline Epidural hematoma & 20 & $20(100 \%)$ & $0(0 \%)$ & $0(0 \%)$ & $0(00-18.4)$ & 0 \\
\hline Overall & 185 & $146(79 \%)$ & $29(15 \%)$ & $3(2 \%)$ & $7(3.8 \%[95 \% \mathrm{Cl} 1.5-7.8 \%])$ & $3(2 \%)$ \\
\hline * 95\% Cls for Poisson distribution. & & & & &
\end{tabular}


TABLE 3. Results of outpatient follow-up imaging and examination

\begin{tabular}{cc}
\hline Patient Follow-Up & No. of Patients (\%) \\
\hline No. of patients & 185 \\
\hline Outpatient CT & \\
\hline Resolved & $146(79)$ \\
\hline Improved & $29(15)$ \\
\hline Stable & $3(2)$ \\
\hline Worse & $7(4)$ \\
\hline Outpatient clinical exam & \\
\hline Improvement & $132(71)$ \\
\hline Stable & $50(27)$ \\
\hline Worse & $3(2)$ \\
\hline
\end{tabular}

ventricular hemorrhage, and trace traumatic subarachnoid hemorrhage after receiving a blunt trauma. The patient presented to the neurosurgical service while intubated with GCS score 9. She had multiple other injuries and was followed in the hospital for 13 days with stable repeat CT scans of her head prior to discharge. At the time of discharge, the patient had returned to her baseline neurological function. At her 1-month follow-up visit, however, the patient was noted to be confused. Her imaging revealed a small right frontal subdural hygroma with slight mass effect against the right frontal lobe, for which she was treated with bur hole drainage with a prompt return to baseline.

\section{Case 3}

This 36-year-old man presented after a blunt trauma with a left frontotemporoparietal acute subdural hematoma measuring $6 \mathrm{~mm}$ at its thickest portion with a leftto-right midline shift of $3 \mathrm{~mm}$. The patient presented to the neurosurgical service while intubated with GCS score 8. An intracranial pressure monitor was placed, revealing normal intracranial pressure. The patient remained in the hospital for 51 days, because of multiorgan system trauma and severe TBI secondary to diffuse axonal injury. The patient had stable repeat CT scans of the head through- out his hospitalization. Upon follow-up evaluation as an outpatient, his family stated that he had become less alert. Imaging at that time revealed the resolution of his subdural hematoma but a new finding of hydrocephalus. A ventriculoperitoneal shunt was placed that resulted in neurological improvement, and the patient's subsequent follow-up imaging at 1 month revealed a marked decrease in ventricular size (Fig. 1).

The other 4 patients with worsening on their follow-up imaging were clinically stable and received no interventions, as subsequent imaging approximately 1-3 months later was stable or improved (Table 3). The details of all patients with worsening on follow-up CT are listed in Table 4 .

\section{Outcomes, Cost of Treatment, and Radiation Exposure}

There were no deaths in our study related to follow-up treatment, with the exception of the patient who was placed in hospice. All patients who were seen on follow-up at 30 days were neurologically stable or improved compared with their baseline at hospital discharge, except for the 3 patients for whom we recommended surgical intervention. The 2 patients who underwent surgical intervention ultimately improved. The patient whose family elected hospice care had nutritional support withheld and he later died.

All patients underwent a CT study of the head at their follow-up visit, incurring a cost of approximately $\$ 700$ per imaging study. For the 185 patients included in the study, this resulted in a total cost of $\$ 129,500$. Additionally, the typical radiation dosage of a CT scan of the head is $2 \mathrm{mSv}$ on average, which is equivalent to 100 chest radiographs or 243 days of natural background radiation exposure. ${ }^{11}$

\section{Discussion}

The utility of CT imaging for TBI patients at presentation and during hospitalization has been examined in several studies. There have been many studies performed with clear guidelines about when to image patients who present with head trauma. ${ }^{8,13,15-19}$ Other studies have assessed early follow-up imaging for inpatients, which were
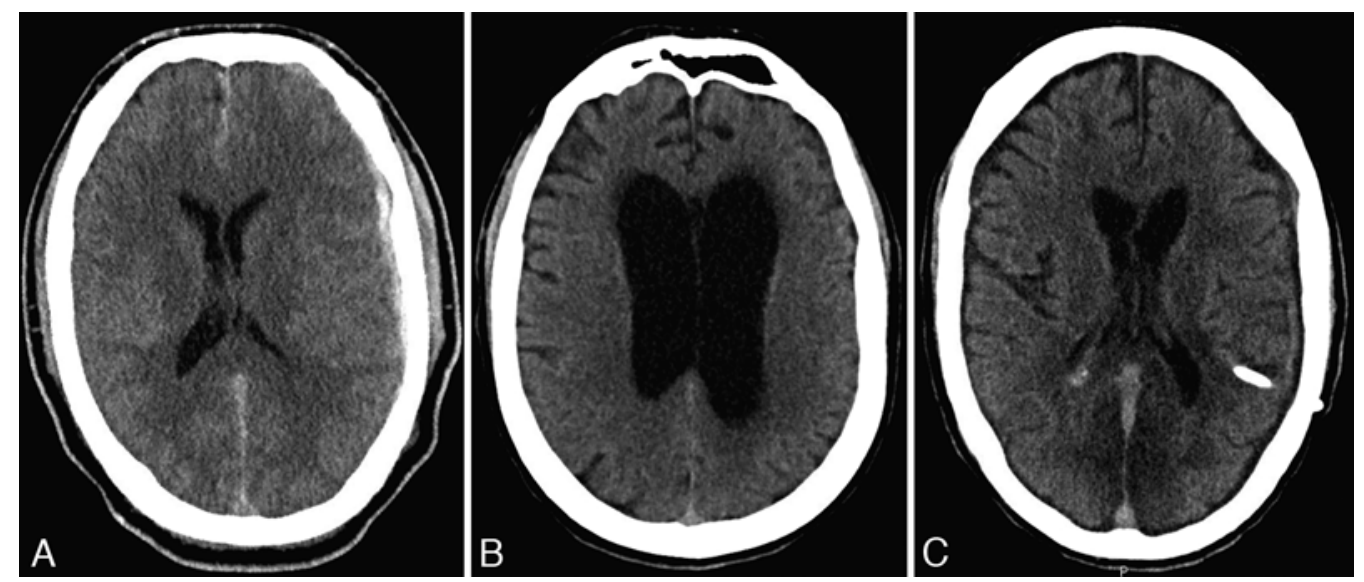

FIG. 1. Case 3. A: Axial CT of the head showing a left-sided subdural hematoma after trauma. B: Repeat axial CT obtained 31 days after initial imaging showing marked ventricular enlargement. C: Repeat axial CT following ventriculoperitoneal shunt placement and improved neurological examination. 


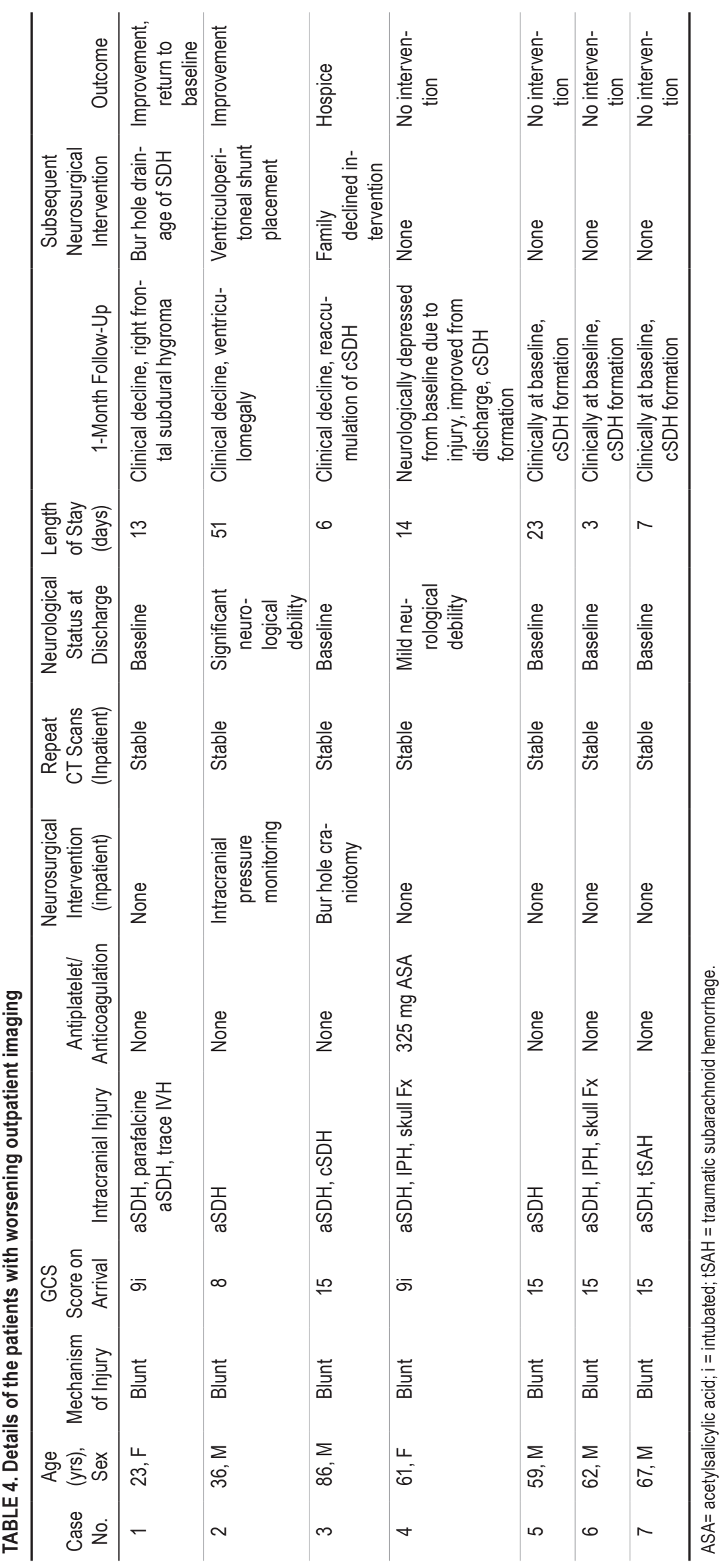


performed within 12 to 48 hours of the original injury with varying conclusions. ${ }^{1,2,4-6,9,13,20,21}$ The indications for follow-up imaging of TBI patients when they are seen in the office after discharge remain unclear.

Our analysis of the patients treated at our Level 1 trauma center for TBI during a 1-year time period included 185 patients who returned with outpatient imaging. Seven of these patients (4\%) showed worsening on follow-up imaging, but surgical intervention was recommended only for the $3(2 \%)$ patients who also exhibited clinical deterioration. Four patients $(2 \%)$ had worsening imaging findings, but no associated clinical deterioration-all of these patients were managed conservatively. These findings suggest that outpatient imaging may be of little value for TBI patients who do not also exhibit clinical worsening.

A review of the literature revealed at least 4 large recent studies or meta-analyses that evaluated the efficacy of inpatient repeat CT following blunt head trauma. ${ }^{1,9,12,20}$ These studies focused on early repeat imaging but did not address outpatient follow-up imaging to detect delayed changes such as chronic subdural hematomas, subdural hygromas, or hydrocephalus. Nonetheless, these studies did find that neurosurgical interventions in hospitalized TBI patients are typically based on clinical changes in most circumstances. Hollingworth et al. ${ }^{9}$ retrospectively evaluated children admitted to their trauma center over a 9-year period and found that early repeat CT-within 24 hours-was frequently worse in patients at a rate of $30 \%$. Worsened imaging, however, rarely resulted in neurosurgical intervention without associated clinical worsening. Stippler et al. ${ }^{20}$ performed a meta-analysis of 74 existing studies between 1999 and 2011 and found worsened radiographic findings on $20 \%$ of early repeat CT scans, but these imaging studies did not predict the need for neurosurgical intervention unless they were ordered in response to a decline in neurological status. Almenawer et al. ${ }^{1}$ performed both a retrospective study and a meta-analysis of the utility of early repeat CT scans of the head in patients with mild TBI and found no benefit in patients with a stable or improved examination. Finally, Reljic et al. ${ }^{12}$ performed a meta-analysis of 41 studies with 10,501 patients to evaluate the utility of early repeat CT scans of the head in TBI patients and found that these imaging studies rarely resulted in a change in patient management. These large studies suggest that repeat imaging studies in the early timeframe are rarely beneficial in the absence of clinical deterioration. ${ }^{1,9,12,20,21}$ Our study of outpatient imaging is in agreement with this principle, as no patients without clinical deterioration required intervention.

Our results suggest that CT imaging of TBI patients should be performed selectively in the outpatient setting. All of the patients in whom delayed surgical intervention was recommended had subdural hematomas on presentation, and all but 1 patient with worsening outpatient imaging had a subdural hematoma on initial imaging, suggesting that this pathology may be more likely to lead to delayed complications than epidural, intraparenchymal, or subarachnoid hemorrhage. If outpatient imaging was restricted to patients presenting with subdural hematoma, then over half of the studies would have been avoided. A more stringent protocol might restrict outpatient imaging to patients with worsening neurological signs or symp- toms. In our study, this strategy would have allowed 182 (98\%) patients to avoid the costs and radiation exposure associated with a follow-up imaging study. This would have resulted in a savings of at least $\$ 127,400$ in health care expenditures. Our TBI patients underwent an average of 3 CT scans of the head during their hospitalization, in addition to many other imaging studies of other parts of the body. Given the recent concern regarding delayed cancer formation, cataract formation, and other consequences of radiation exposure, reducing imaging studies would likely be beneficial to this patient population. $3,7,14$

The limitations of our study include its retrospective design and the limited number of patients in certain subgroups. Of the 422 patients who survived their TBI until discharge, only $185(44 \%)$ patients returned for their scheduled clinic visit, so our results may not apply to the general population of TBI survivors. Nonetheless, this should not bias our conclusions because this study is strictly concerned with the appropriate imaging of the subpopulation of TBI patients who are willing and able to return for a clinic appointment. Additionally, even though our results suggest that routine outpatient imaging of all TBI patients is unnecessary, this study is not sufficient to create evidence-based guidelines for follow-up imaging. Imaging is certainly appropriate for patients with clinical deterioration or failure to improve as expected. Conversely, patients who returned to baseline at follow-up, or those who had only mild findings on inpatient imaging such as traumatic subarachnoid hemorrhage, are very unlikely to benefit from additional imaging. We speculate that the optimal strategy might be to defer most outpatient follow-up imaging until after the initial clinic visit, so that the decision is guided by the physician's clinical impression of the patient.

\section{Conclusions}

In our retrospective study of 185 TBI patients, we found no clear value of routine outpatient follow-up imaging in the absence of clinical deterioration. Delayed interventions were triggered by worsening neurological symptoms rather than isolated imaging findings. These results suggest that a selective approach to outpatient imaging after TBI should allow for appropriate patient care, while also delivering significant financial and public health benefits. Additional prospective studies could further refine the appropriate criteria for outpatient imaging after TBI.

\section{References}

1. Almenawer SA, Bogza I, Yarascavitch B, Sne N, Farrokhyar F, Murty N, et al: The value of scheduled repeat cranial computed tomography after mild head injury: single-center series and meta-analysis. Neurosurgery 72:56-64, 2013

2. Bee TK, Magnotti LJ, Croce MA, Maish GO, Minard G, Schroeppel TJ, et al: Necessity of repeat head CT and ICU monitoring in patients with minimal brain injury. J Trauma 66:1015-1018, 2009

3. Bhargavan M, Sunshine JH: Utilization of radiology services in the United States: levels and trends in modalities, regions, and populations. Radiology 234:824-832, 2005

4. Brown CV, Weng J, Oh D, Salim A, Kasotakis G, Demetriades D, et al: Does routine serial computed tomography of the head influence management of traumatic brain injury? A prospective evaluation. J Trauma 57:939-943, 2004 
5. Brown CV, Zada G, Salim A, Inaba K, Kasotakis G, Hadjizacharia $P$, et al: Indications for routine repeat head computed tomography (CT) stratified by severity of traumatic brain injury. J Trauma 62:1339-1345, 2007

6. Chao A, Pearl J, Perdue P, Wang D, Bridgeman A, Kennedy $S$, et al: Utility of routine serial computed tomography for blunt intracranial injury. J Trauma 51:870-876, 2001

7. Fazel R, Krumholz HM, Wang Y, Ross JS, Chen J, Ting HH, et al: Exposure to low-dose ionizing radiation from medical imaging procedures. N Engl J Med 361:849-857, 2009

8. Haydel MJ, Preston CA, Mills TJ, Luber S, Blaudeau E, DeBlieux PM: Indications for computed tomography in patients with minor head injury. N Engl J Med 343:100-105, 2000

9. Hollingworth W, Vavilala MS, Jarvik JG, Chaudhry S, Johnston BD, Layman S, et al: The use of repeated head computed tomography in pediatric blunt head trauma: factors predicting new and worsening brain injury. Pediatr Crit Care Med 8:348-357, 2007

10. Langlois JA, Rutland-Brown W, Wald MM: The epidemiology and impact of traumatic brain injury: a brief overview. $\mathbf{J}$ Head Trauma Rehabil 21:375-378, 2006

11. Mettler FA Jr, Huda W, Yoshizumi TT, Mahesh M: Effective doses in radiology and diagnostic nuclear medicine: a catalog. Radiology 248:254-263, 2008

12. Reljic T, Mahony H, Djulbegovic B, Etchason J, Paxton H, Flores M, et al: Value of repeat head computed tomography after traumatic brain injury: systematic review and metaanalysis. J Neurotrauma 31:78-98, 2014

13. Sifri ZC, Livingston DH, Lavery RF, Homnick AT, Mosenthal AC, Mohr AM, et al: Value of repeat cranial computed axial tomography scanning in patients with minimal head injury. Am J Surg 187:338-342, 2004

14. Smith-Bindman R, Miglioretti DL, Larson EB: Rising use of diagnostic medical imaging in a large integrated health system. Health Aff (Millwood) 27:1491-1502, 2008

15. Stein SC, Ross SE: Minor head injury: a proposed strategy for emergency management. Ann Emerg Med 22:11931196,1993

16. Stiell IG, Clement CM, Rowe BH, Schull MJ, Brison R, Cass D, et al: Comparison of the Canadian CT Head Rule and the New Orleans Criteria in patients with minor head injury.

JAMA 294:1511-1518, 2005

17. Stiell IG, Lesiuk H, Wells GA, Coyle D, McKnight RD, Bri- son R, et al: Canadian CT head rule study for patients with minor head injury: methodology for phase II (validation and economic analysis). Ann Emerg Med 38:317-322, 2001

18. Stiell IG, Lesiuk H, Wells GA, McKnight RD, Brison R, Clement C, et al: The Canadian CT Head Rule Study for patients with minor head injury: rationale, objectives, and methodology for phase I (derivation). Ann Emerg Med 38:160-169, 2001

19. Stiell IG, Wells GA, Vandemheen K, Clement C, Lesiuk H, Laupacis A, et al: The Canadian CT Head Rule for patients with minor head injury. Lancet 357:1391-1396, 2001

20. Stippler M, Smith C, McLean AR, Carlson A, Morley S, Murray-Krezan C, et al: Utility of routine follow-up head CT scanning after mild traumatic brain injury: a systematic review of the literature. Emerg Med J 29:528-532, 2012

21. Wang MC, Linnau KF, Tirschwell DL, Hollingworth W: Utility of repeat head computed tomography after blunt head trauma: a systematic review. J Trauma 61:226-233, 2006

\section{Disclosure}

The authors report no conflict of interest concerning the materials or methods used in this study or the findings specified in this paper.

\section{Author Contributions}

Conception and design: Befeler, Sorenson. Acquisition of data: Befeler, Gordon. Analysis and interpretation of data: Befeler, Gordon, Sorenson. Drafting the article: Befeler. Critically revising the article: Befeler, Gordon, Sorenson. Reviewed submitted version of manuscript: all authors. Approved the final version of the manuscript on behalf of all authors: Befeler. Statistical analysis: Befeler, Gordon, Sorenson. Administrative/technical/material support: Befeler, Gordon, Khan, Sorenson. Study supervision: Befeler, Fernandez, Muhlbauer, Sorenson.

\section{Correspondence}

Adam Befeler, Department of Neurosurgery, University of Tennessee Health Science Center, 847 Monroe Ave, Ste. 427, Memphis, TN 38163.email: befeler@gmail.com. 